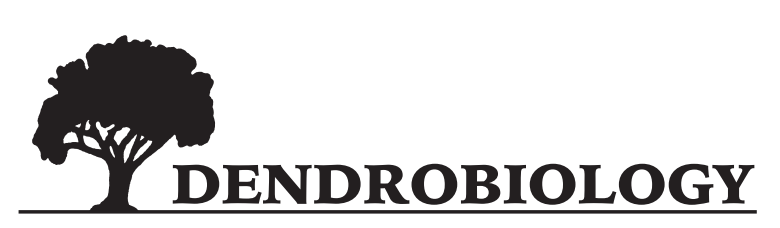

2020, vol. 83, 52-59

http://dx.doi.org/10.12657/denbio.083.005

\author{
Evgeniya Zhuk, Galina Vasilyeva, Sergey Goroshkevich
}

\title{
Mutational witches' broom impact on the growth of the parent branch in several Pinaceae species
}

Received: 28 January 2020; Accepted: 15 June 2020

\begin{abstract}
Mutational witches' broom is a part of the tree crown with abnormally dense branching and slow shoot growth, which putatively originates from a cell in a bud apical meristem and can be visually differentiated from the normal crown. The witches' broom forms a large branching system which competes sufficiently with other parts of the tree crown. However, the competitive relationship and the interaction between the mutant and normal crown parts have not yet been studied. We investigated the patterns and dynamics of the competitive relationship between witches' broom and normal branching systems of the same tree of five Pinaceae species by tree ring analysis. Three saw-cuts were made in each tree: on the lateral branch with the witches' broom, on the proximal part of the axial branch in front of the branch with the witches' broom, on the distal part of the axial branch right after the branch with the witches' broom. Annual radial growth was measured to the nearest $0.01 \mathrm{~mm}$, and annual ring areas from three saw-cuts were analysed to compare the growth dynamics before and after witches' broom appearance. The growth of the lateral branch with the witches' broom sharply increased in the year of witches' broom appearance by 2-10 times. The growth of the distal part of the axial branch sharply decreased in the same year, which could be explained only by the witches' broom appearance. All branches with witches' brooms gradually became thicker than the distal part of the branch, 3-150 times at the peak of growth, and occasionally outgrew even the proximal part of the branch. Thus, witches' broom is drastically morphologically and physiologically different from the rest of the crown. All witches' brooms had their own vertically oriented axis of symmetry and represented autonomous branching systems that were not subordinate to any other branching systems. They break the normal donor-acceptor relationship in a tree and eagerly consume resources without being fully involved in their production. The mutation clearly affects the hormonal regulation of growth and morphogenesis and turns a witches' broom into a new metabolic sink.
\end{abstract}

Keywords: somatic mutation, annual rings, crown part interaction

Address: E. Zhuk, G. Vasilyeva, S. Goroshkevich, Institute of Monitoring of Climatic and Ecological Systems, Siberian Branch of the Russian Academy of Sciences, 10/3, Akademichesky Ave., Tomsk, Russia, e-mail: eazhuk@yandex.ru

\section{Introduction}

Witches' broom (WB) is defined as a part of the tree crown with abnormally dense branching and slow shoot growth, visually differing from the normal crown (NC) (Fig. 1). Formation of WB can be caused by two factors. The first factor is fungal or microbial infection (Ghosh et al., 1999; Yun et al., 2009). Pathological WB usually has an unhealthy appearance, depressed reproduction and a short life span, with a focal distribution (Hogenhout et al., 2008; Mayr et al., 2010).

The second factor is a somatic mutation that putatively occurred in the apical meristem of a bud. As 
evidenced, seed progeny of WB segregate in a $1: 1$ ratio of dwarf vs normal seedlings (Liernur, 1927; Duffield \& Wheat, 1963; Johnson et al., 1968; Waxman, 1975). Mutational WB has a healthy appearance, a normal reproduction and a long life span (Buckland \& Kuijt, 1957; Fordham, 1967). Generally, it is sporadically distributed, with an approximate occurrence of one per 5-10 thousand trees (Yamburov \& Goroshkevich, 2007). The main differences between WB an NC are increased branching, reduced shoot length and decreased apical dominance (Zhuk et al., 2015). Mutational WB is a principal source of plant genetic material for ornamental and dwarf cultivars in tree breeding, especially in conifers (Farjon, 2017).

Although WB most likely originates from a single cell in an apical meristem (Duffield \& Wheat, 1963; Grasso, 1969), the mutation manifests phenotypically in the formation of a large or even huge branching system, which competes sufficiently with the other parts of the tree crown. However, the competitive relationship and the interaction between WB and NC have not yet been studied. Our visual observations showed that the branch at the base of the WB is much thicker than the surrounding branches. It can be assumed that a large and vigorous WB somehow

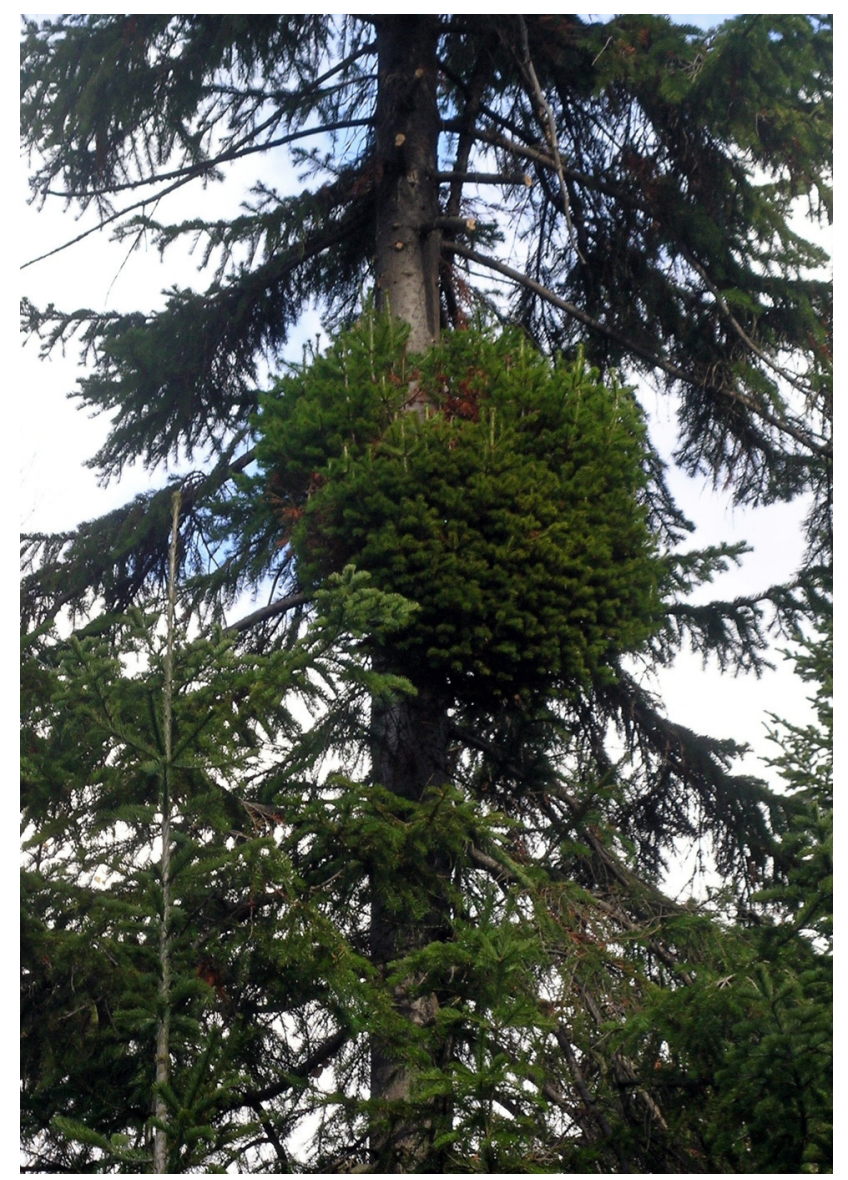

Fig. 1. Mutational witches' broom in Abies sibirica Ledeb. (for more detail see Table 1) attracted too many resources from the rest of the crown possibly depriving it. Such interaction can be a long process, as the life span of WB is estimated in dozens or even hundreds of years. Therefore, direct observations in this case are hardly possible. Retrospective reconstruction of the dynamics of tree vital activity is traditionally carried out by counting and measuring of tree rings. In this context, the aim of this study was to investigate the pattern and dynamics of the competitive relationship between WB and normal branching systems of the same tree of several Pinaceae species by means of tree ring analysis.

\section{Material and methods}

Plant material was collected from 11 trees belonging to five Pinaceae species and bearing mutational WB (Table 1). These trees grew in different parts of the Asian part of Russia, with different environmental conditions. All trees with WB were from the first stand layer and had a healthy appearance. Parental tree age was determined by the analysis of cores taken from the tree trunk at $50 \mathrm{~cm}$ above the ground. Dimensions and positions of WBs in the parental tree crowns were essentially different. The WBs were located in different parts of the crown, from the lower shaded part to the upper lighted one. We evaluated WB density by eye compared to the neighbour $\mathrm{NC}$ branch of the same tree. The WB crown density was classified as "low" when it was less than twice as dense as the NC, as "medium" when it was 2-3 times denser than the NC, and as "high" when it was more than three times as dense as the NC (Zhuk et al., 2015). Abundant drying of large parts of the WB crown was noted in P. sibirica-2, $-4,-5, A$. sibirica and L. gmelinii-2 because of their extreme density.

Three saw-cuts were made in each tree: lateral branch with WB (LBWB), proximal part of axial branch (PPAB) and distal part of axial branch (DPAB) (Fig. 2). The distance between proximal and

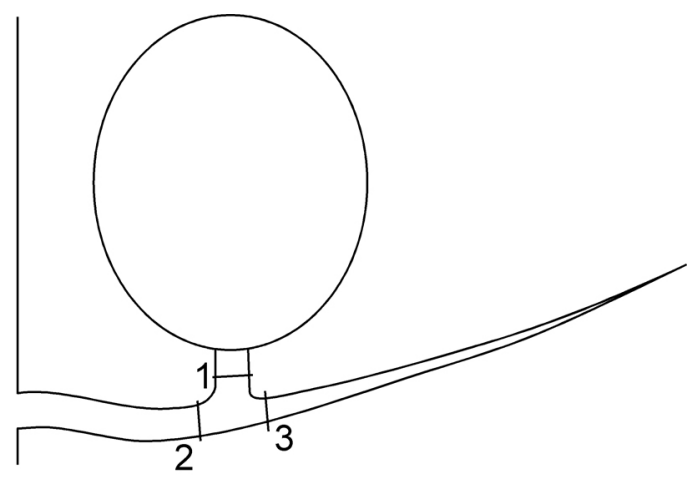

Fig. 2. Plan of saw-cuts in the branch bearing the witches' broom. 1 - lateral branch with witches' broom, 2 - proximal part of axial branch, 3 - distal part of axial branch 
distal saw-cuts was $2-3 \mathrm{~cm}$ from LBWB. Annual radial growth was measured to the nearest $0.01 \mathrm{~mm}$ using an MBS-9 microscope (ASMA-Pribor, Russia). The horizontal branch surface was considered as a circle. Annual ring area was calculated as the area of ring from the circle area. Annual ring area from three different parts near WB for all trees and all years was used as raw data and analysed to compare the dynamics of annual growth before and after WB formation. Series were not standardised because no chronology statistics were made.

\section{Results}

Basically, the diameter of the WB branch depended on its age (Table 1). In the same species, WBs of a similar age had a large branch thickness when they grew in the upper part of the crown in full light and when crown density was high.

In the crown of an ordinary tree, there is always one dominant pole and one axis of symmetry, namely a strictly orthotropic leading shoot. The other branches are subordinate to it, organised hierarchically, oriented at an angle to the gravity vector and with only lateral symmetry. Without exception, all WBs, even the weakest and the shaded ones, fundamentally differed from any other local branching system because they had their own vertically oriented axis of symmetry and represented autonomous branching systems that were not subordinate to any other branching system.

In $P$. sibirica-1, -2 and -3 , the number of tree rings in the PPAB and the LBWB was one more than in the DPAB (Fig. 3A-3C). This means that the lateral branch, on which the WB subsequently formed, arose from the usual bud. The WB in P. sibirica-1 was very young, providing the opportunity to accurately trace its growth trend back and compare it with the growth of the maternal branch. The first annual shoot in 2012 was normal and ended with one terminal and several lateral buds. In spring 2013, all these buds began to grow and formed one terminal and several lateral shoots. Typically, a terminal shoot significantly exceeds all lateral shoots in diameter. In this case, one of the lateral shoots became abnormally thick, 6 times larger than that in the terminal shoot. This lateral shoot was the first annual shoot in the newly formed WB. In 2016, the LBWB annual ring area again increased sharply, while in the DPAB, it began to decline. Thus, by the end of the 4 th year, the annual ring area in the LBWB surpassed that of the DPAD by 7.7 times. In P. sibirica-2 and -3 , similar trends in the growth dynamics with different growth rate of the DPAB and the LBWB after WB formation were also pronounced.

Table 1. Characteristics of trees with witches' broom (WB) in Russia. LBWB - lateral branch with WB, PPAB - proximal part of axial branch, DPAB - distal part of axial branch

\begin{tabular}{|c|c|c|c|c|c|c|c|c|c|c|c|}
\hline$\stackrel{0}{\tilde{U}}$ & 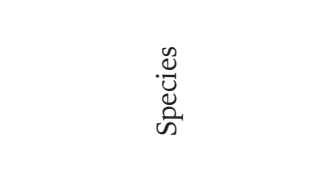 & 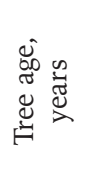 &  & 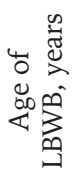 & 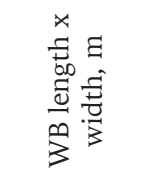 &  & $\begin{array}{l}\text { 离 } \\
\frac{1}{0} \\
0 \\
\sum^{n}\end{array}$ & 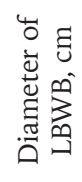 & 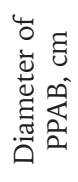 & 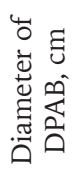 & 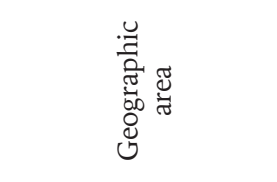 \\
\hline P. sibirica-1 & Pinus sibirica Du Tour & 60 & 5 & 4 & $0.25 \times 0.25$ & $\begin{array}{l}\text { Bot- } \\
\text { tom* }\end{array}$ & - & 2.6 & 3.1 & 1.2 & $\begin{array}{l}\text { West Siberian plain } \\
\left(56^{\circ} 30^{\prime} \mathrm{N}, 84^{\circ} 38^{\prime} \mathrm{E}\right)\end{array}$ \\
\hline P. sibirica-2 & Pinus sibirica Du Tour & 220 & 42 & 41 & $0.90 \times 1.00$ & Bottom & High & 9.4 & 13.2 & 4.1 & $\begin{array}{c}\text { Western Sayan } \\
\left(52^{\circ} 30^{\prime} \mathrm{N}, 90^{\circ} 00^{\prime} \mathrm{E}\right)\end{array}$ \\
\hline P. sibirica-3 & Pinus sibirica Du Tour & 220 & 37 & 36 & $1.30 \times 0.90$ & Bottom & Low & 10.6 & 14.2 & 10.9 & $\begin{array}{c}\text { Western Sayan } \\
\left(52^{\circ} 30^{\prime} \mathrm{N}, 90^{\circ} 00^{\prime} \mathrm{E}\right)\end{array}$ \\
\hline P. sibirica-4 & Pinus sibirica Du Tour & 170 & 37 & 19 & $1.10 \times 1.10$ & Top & Medium & 7.9 & 10.8 & 7.1 & $\begin{array}{l}\text { West Siberian plain } \\
\left(56^{\circ} 30^{\prime} \mathrm{N}, 84^{\circ} 38^{\prime} \mathrm{E}\right)\end{array}$ \\
\hline P. sibirica-5 & Pinus sibirica Du Tour & 240 & 54 & 22 & $1.10 \times 1.20$ & Bottom & High & 8.6 & 9.1 & 2.8 & $\begin{array}{c}\text { Western Sayan } \\
\left(52^{\circ} 30^{\prime} \mathrm{N}, 90^{\circ} 00^{\prime} \mathrm{E}\right)\end{array}$ \\
\hline P. sylvestris & Pinus sylvestris L. & 120 & 54 & 48 & $1.20 \times 1.30$ & Top & High & 14.6 & 18.1 & 8.9 & $\begin{array}{c}\text { Severomuyskiy Range } \\
\left(56^{\circ} 15^{\prime} \mathrm{N}, 112^{\circ} 48^{\prime} \mathrm{E}\right)\end{array}$ \\
\hline P. obovata & Picea obovata Ledeb. & 180 & 48 & 29 & $0.25 \times 0.40$ & Bottom & Low & 4.9 & 7.8 & 5.6 & $\begin{array}{c}\text { Severomuyskiy Range } \\
\left(56^{\circ} 15^{\prime} \mathrm{N}, 112^{\circ} 48^{\prime} \mathrm{E}\right)\end{array}$ \\
\hline A. sibirica & Abies sibirica Ledeb. & 160 & 35 & 22 & $0.60 \times 0.65$ & Bottom & Medium & 2.6 & 3.9 & 2.4 & $\begin{array}{l}\text { Baikalskiy Range } \\
\left(55^{\circ} 40^{\prime} \mathrm{N}, 109^{\circ} 00^{\prime} \mathrm{E}\right)\end{array}$ \\
\hline L. gmelinii-1 & $\begin{array}{l}\text { Larix gmelinii var. japonica } \\
\text { (Maxim.ex Regel) Pilg. }\end{array}$ & 80 & 32 & 16 & $0.55 \times 0.60$ & Bottom & Medium & 3.3 & 4.2 & 2.4 & $\begin{array}{l}\text { Southern part of } \\
\text { Sakhalin Island } \\
\left(46^{\circ} 50^{\prime} \mathrm{N}, 142^{\circ} 44^{\prime} \mathrm{E}\right)\end{array}$ \\
\hline L. gmelinii-2 & $\begin{array}{l}\text { Larix gmelinii var. gmelinii } \\
\text { (Rupr.) Kuzen. }\end{array}$ & 220 & 102 & 69 & $1.60 \times 1.90$ & Bottom & Medium & 11.5 & 14.9 & 11.7 & $\begin{array}{c}\text { Severomuyskiy Range } \\
\left(56^{\circ} 15^{\prime} \mathrm{N}, 112^{\circ} 48^{\prime} \mathrm{E}\right)\end{array}$ \\
\hline L. gmelinii-3 & $\begin{array}{l}\text { Larix gmelinii var. gmelinii } \\
\text { (Rupr.) Kuzen. }\end{array}$ & 320 & 241 & 107 & $1.80 \times 2.10$ & Bottom & Medium & 11.6 & 15.0 & 11.4 & $\begin{array}{c}\text { Severomuyskiy Range } \\
\left(56^{\circ} 15^{\prime} \mathrm{N}, 112^{\circ} 48^{\prime} \mathrm{E}\right)\end{array}$ \\
\hline
\end{tabular}

* In spite of lower position of WB, the light level was fairly high. 


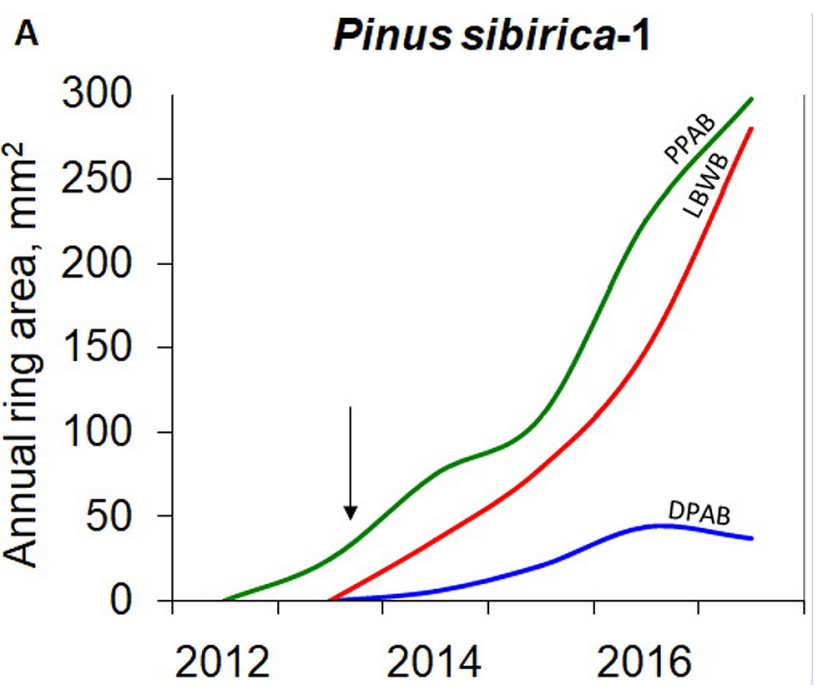

B

Pinus sibirica-2

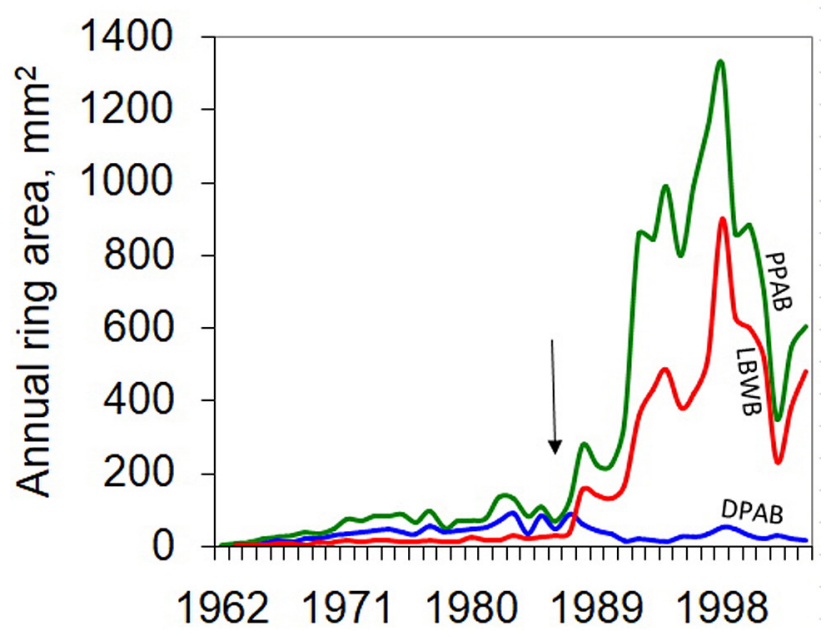

C

Pinus sibirica-3

D

Pinus sibirica-4
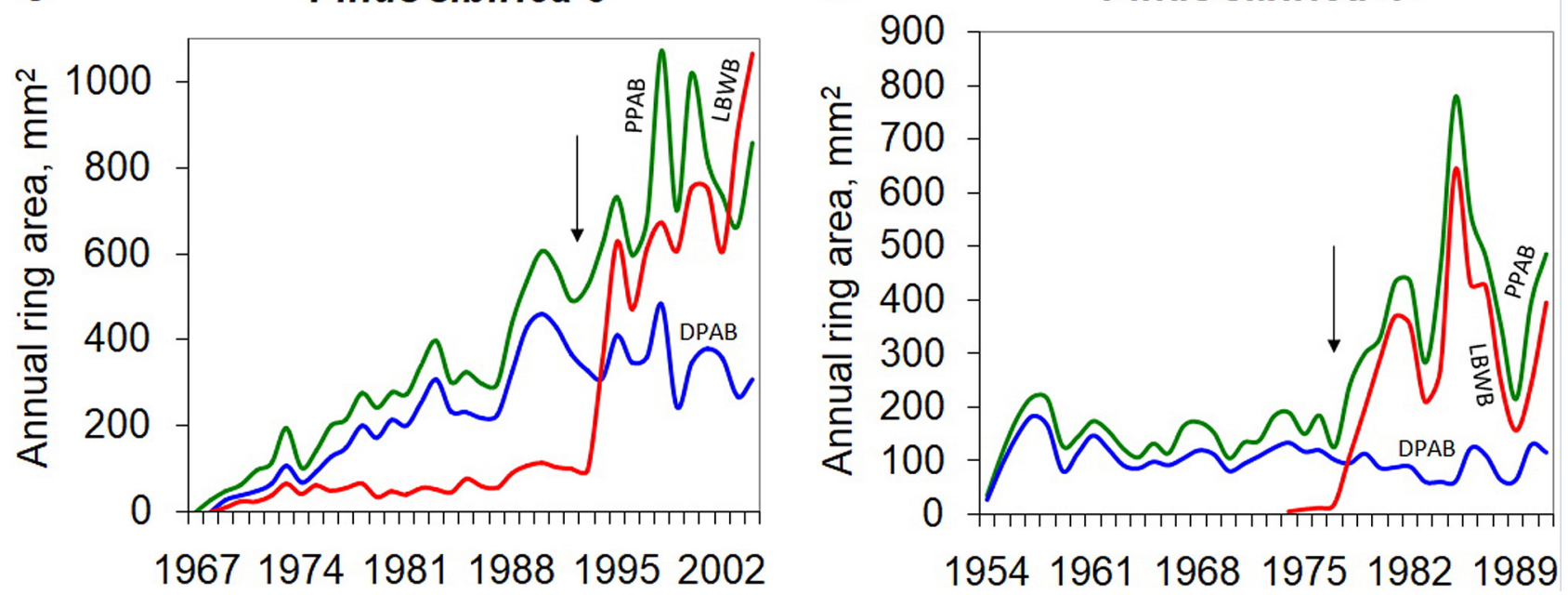

195419611968197519821989


Fig. 3. Growth dynamics of tree ring area in proximal part of axial branch - PPAB (green), distal part of axial branch DPAB (blue) and lateral branch with witches' broom - LBWB (red) in A - Pinus sibirica-1; B - Pinus sibirica-2; C - Pinus sibirica-3; D - Pinus sibirica-4; E - Pinus sibirica-5; F - Pinus sylvestris. The arrow shows the year of the witches' broom formation 

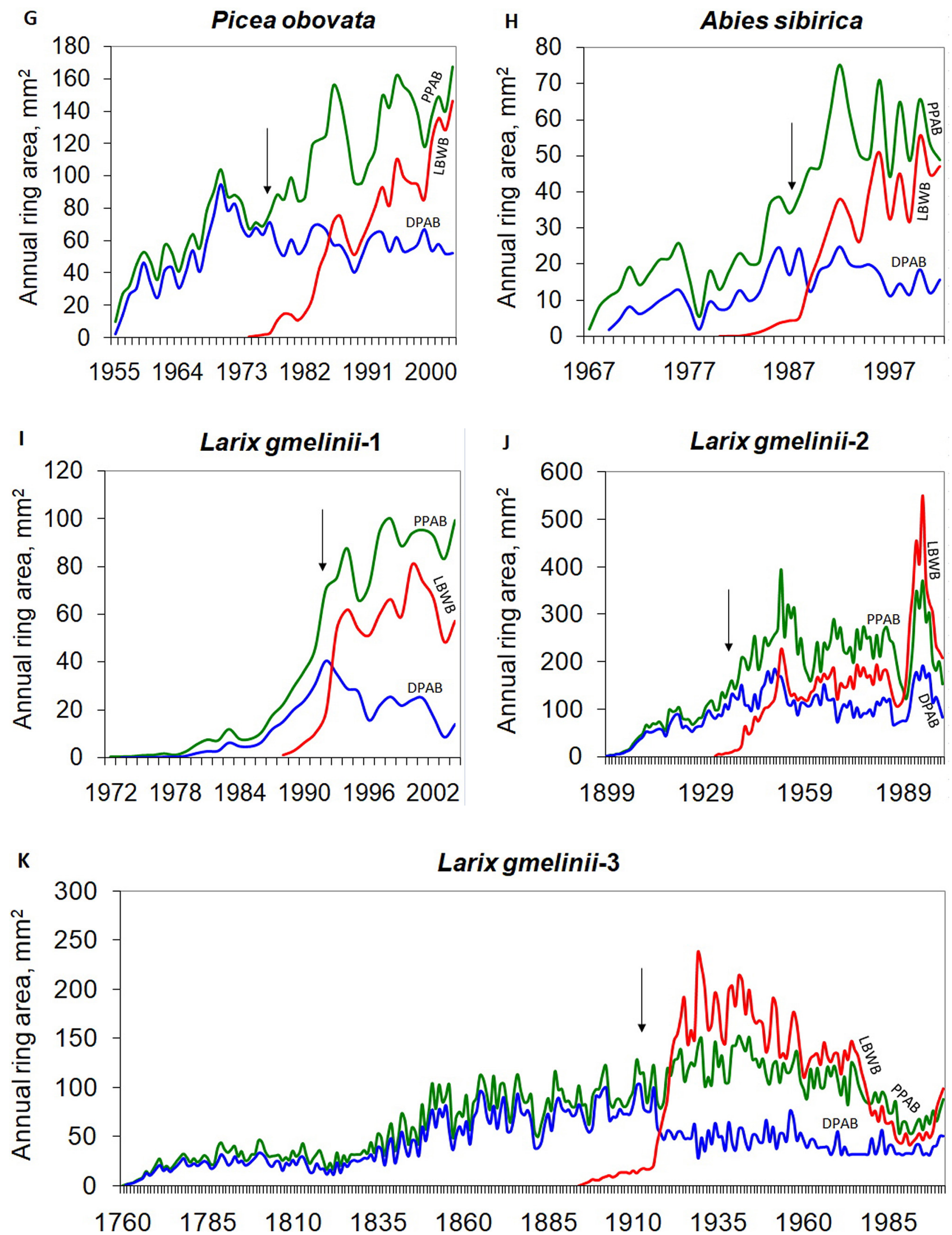

Fig. 3. Growth dynamics of tree ring area in proximal part of axial branch - PPAB (green), distal part of axial branch DPAB (blue) and lateral branch with witches' broom - LBWB (red) in G - Picea obovata, H - Abies sibirica, I - Larix gmelinii-1, J - Larix gmelinii-2, K - Larix gmelinii-3. The arrow shows the year of the witches' broom formation 
In all other cases (Fig. 3D-3K), the number of growth rings in the LBWB was significantly lower than that in the DPAB, and the size of the first rings was relatively small. This means that all LBWBs originated either from brachyblasts or from latent buds. In each of these specimens, the growth of the lateral branch prior to WB formation was extremely slow. The WB formation was well marked by a sharp (over 1 year) increase in lateral branch growth, which cannot be explained by any other reasons. The growth of the LBWB continued to increase rapidly after WB formation. This increase was not exclusively progressive, but cyclical, when in some years, the growth decreased compared to the previous year. In P. sibirica-5, L. gmelinii-2 and L. gmelinii-3, the LBWB outperformed the PPAB. At the same time, a sharp decrease in growth began in the DPAB. In P. sylvestris, the DPAB died in the 21 st year after WB appearance due to nutrient and water deprivation, as the supply was locked in the WB.

Based on these results, we suggest that the WB arises from the buds from any crown part (top, middle, bottom) on branches of any size and origin: from ordinary branches with good growth to the smallest branches with barely expressed growth, which were formed shortly before from the latent buds. According to our observations, a WB has never arisen from large buds, perhaps because the proportion of such buds is negligible, and the WB formation in any bud is equally probable.

In all cases, the reconstruction of the year of WB formation by the annual rings does not raise any doubt: the LBWB growth sharply increases in this year by $2-10$ times, usually by $3-4$ times. This phenomenon never happens with the usual intact branches for the climatic causes. The year of WB formation is marked even more reliably by a sharp decrease in DPAB growth, which cannot be explained by any other reasons, especially if we consider it in comparison with PPAB growth.

In the first years after WB formation, the LBWB growth continued to increase more or less rapidly. The period of growth increase took 15-20 years on average, ranging from 8 to 54 years. During this time, the LBWB growth increasing many times in comparison with the state prior to WB formation, ranging from 4.5 to 140 times. The LBWB outperformed the DPAB 3-150 times at the peak of growth. In the extreme case, which was the only one among our samples, the DPAB died after a critical decrease in growth.

The heterogeneity of our material does not allow us to correctly identify the nature of the WB diversity according to aggressiveness. However, it is obvious that there are both external and internal factors of diversity.

The relative LBWB growth rate after WB formation clearly depended on the initial growth rate.
When the WB appeared on medium-sized branches, LBWB growth increased by several times; in contrast, when it appeared on small branches, growth increased by dozens of times. For the same reason, the relative LBWB growth rate was higher when the WB was located in the lower part of the crown, where the branch growth was low. To a certain extent, the absolute LBWB growth rate and the WB size depended on the position in the tree crown; WBs from the upper, well-lit crown part were generally larger.

After WB formation, some LBWBs, unlike ordinary branches, had sharp growth fluctuations: growth decreased by 3-5 times over 3-5 years. This was mainly observed for $P$. sibirica, $A$. sibirica and $L$. gmelinii and was clearly associated with the massive drying of large fragments of the WB due to its excess density, which was noted during sample collection. The densest parts of the WB were inhabited by pests and gradually died over several years. Due to this phenomenon, the annual increments decreased and then completely or partially restored over time.

\section{Discussion}

Witches' brooms are formed from scratch and can be distinguished from the normal part of the crown. If the WB is located in an advantageous place, for example, on top of a tree, it may even take a dominant position in the tree crown (Yamburov \& Goroshkevich, 2007). Our results allowed us to quantify the relationship between the WB and the tree crown and to trace their development over time. In all cases, the WB gradually became thicker than the DPAB and, occasionally, than the PPAB. When competing for nutrients with normal branches, the WB was usually the winner. In the literature, there are cases in which the WB looked much more vigorous than the unaffected crown of the same tree (Brown et al., 1994). When grafting to a normal rootstock, the WB scion is often thicker than the rootstock (Zhuk et al., 2015).

The growth dynamics of ordinary branches, like any growth dynamics, develops under the influence of three groups of factors: age-related growth trend, climate, random factors. The age trend usually includes rising, peak and declining growth (Matsushita et al., 2015). The branches in a relatively closed stand usually reach their growth peak quite soon after the start of their life, because branch lighting conditions are rapidly deteriorating (Martínez-Vilalta et al., 2007). Both extreme and intermediate variants were presented in our plant material. There were relatively old branches, which had reached their growth peak long time ago (L. gmelinii-2 and -3), branches with recent growth peaks (P. sibirica-3, P. sylvestris, $L$. 
gmelinii-1) and branches with an absent growth peak or a peak flattened by the WB (P. sibirica-1, $-2,-4,-5$, A. sibirica, P. obovata).

Besides age and individual WB features, their growth rate depends both on the position in the crown and the status of the bearing branch. When the WB is located in the upper crown part, it has a chance to grow huge and take a dominant position on the tree. However, when it is located in the depths of the living crown near the trunk, it will remain small and weak. The better the WB position in the crown, the faster it gains strength and the more it dominates the tree. However, in all cases, the radial growth in the year of WB onset increases dramatically, sometimes by an order of magnitude. The WB appearance is always a kind of explosion in a calmly and progressively developing branching system.

The gap between the age of the LBWB and the PPAB, which was observed in some cases, suggests that the LBWB was formed from the apical meristem of a latent axillary. Previously, it was found that the LBWB in P. sylvestris is most likely to grow from a latent bud, which was observed when analysing the ages of the LBWB, PPAB and DPAB (Yamburov et al., 2016). These authors suggest that the mutation that occurred in a cell of the apical meristem in a latent bud initiates its awakening. However, our data contradict this hypothesis and indicate that the latent bud is released first, forms a small weak branch, which lives for several years, and gains some strength; only after that, it generates a WB. Most likely, there is no connection between the size of the branch or bud and the likelihood of WB formation on its basis. The reason of the high WB occurrence on branches released from latent buds is probably the fact that most of the shoots and buds in the crown are small, making it statistically more likely than the WB formation on a large branch.

Asynchronous growth of the distal and proximal parts of the branch could mainly be explained by the WB appearance, with the exception of some details. An abrupt reduction in the width of annual rings in conifers provides the clearest indication of the damage (Schweingruber, 1988). Such a phenomenon indicates either catastrophic natural phenomena affecting the tree (Kraemer \& Nyland, 2010) or damage to the tree by certain diseases or pests (Schweingruber, 1996). Such damages are typical for all conifer species. A WB itself acts as a disease in relation to the distal branch. The high density of the WB crown, which is beyond of species characteristics, leads to the frequent damage by diseases, and some crown parts die for this reason (Brown et al., 1994). In our case, on the graph of the annual ring area growth, this was expressed in the periods of a sharp decrease in WB growth, which do not coincide with growth dynamics of the proximal and distal parts of the branch. The WB, after the death of its part, temporarily attracted less resources from the distal branch and its growth temporarily increased. After some time, WB phytomass increased again, and the dynamics of ring area growth in all branch parts returned to their previous state.

The effect of mutational WB to the branch radial growth is similar to mistletoe (Viscum album L.) effects to some extent. Pine mistletoe infection leads to crown degradation in its host by reducing the radial increment and affected the needle characteristics (Rigling et al., 2010; Catal \& Carus, 2011; Ozturk et al., 2019). Mistletoe removal leads to increased growth rates of the hosts (Yan et al., 2016), which is similar to the effect of increased growth after the death of the WB part.

The WB is drastically morphologically and physiologically different from the rest of the crown. The WB breaks the normal donor-acceptor relationship in a tree and actively consumes the resources without being involved in their production due to active branching with reduced apical dominance. This suggests that the mutation affects the hormonal regulation of growth and morphogenesis and turns the WB into a new metabolic sink. Against this background, the WB does not just look unusual, it also behaves unusual, like something fundamentally foreign to the normal crown of the tree.

The mutation initiates a complex set of physiological changes, most likely caused by a change in the hormonal balance. This, in turn, leads to changes in morphological development, including an atypical abundance of buds, which further enhances the attracting ability of the WB. Leading shoot apical meristem can act as a strong metabolic sink because of its high growth rate and hormone level, depriving nutrients from latent axillary buds (Cline, 1997; Cline et al., 2009). This leads to an increased influx of nutrients to the LBWB, while the other branches are provided with less nutrients. Normally, cambial growth is harmoniously distributed throughout the branching system, and its work depends on the interaction of the genotype and the environment (Savidge, 2001). This is the basis of both mechanical stability and the optimal allocation of resources along the tree parts. The harmonious distribution of cambial growth is often violated in the WB, mainly due to faster mitotic divisions (Brown et al., 1994): the small centre of abnormal activity cannot organically integrate into the normal system. This indicates the physiological heterogeneity of the WB and the NC, because the WB grows that rapidly that the $\mathrm{NC}$ does not have time to form an adequate "infrastructure" for growth. Therefore, the branch or trunk above the WB first appears outside the active root-leaf exchange, then weakens and sometimes eventually dies. 


\section{Funding}

This study was funded by the Russian Science Foundation, grant No 18-16-00058.

\section{References}

Brown CL, Sommer HE \& Wetzstein H (1994) Morphological and histological differences in the development of dwarf mutants of sexual and somatic origin in diverse woody taxa. Trees 9: 61-66. doi:10.1007/BF00202123.

Buckland DC \& Kuijt J (1957) Unexplained brooming of Douglas-fir and other conifers in British Columbia and Alberta. Forest Science 3: 236-242. doi:10.1093/forestscience/3.3.236.

Catal Y \& Carus S (2011) Effect of pine mistletoe on radial growth of Crimean pine (Pinus nigra) in Turkey. Journal of Environmental Biology 32: 263-270.

Cline M (1997) Concepts and terminology of apical dominance. American Journal of Botany 84: 1064-1069. doi:10.2307/2446149.

Cline MG, Bhave N \& Harrington CA (2009) The possible roles of nutrient deprivation and auxin repression in apical control. Trees 23: 489-500. doi:10.1007/s00468-008-0294-8.

Duffield J \& Wheat J (1963) Dwarf seedlings from broomed douglas-fir. Silvae Genetica 12: 129-133.

Farjon A (2017) A handbook of the world's conifer. 2nd ed. Brill, Leiden-Boston, Netherlands.

Fordham AJ (1967) Dwarf conifers from witches'-brooms. Arnoldia 24: 29-50.

Ghosh DK, Das AK, Singh S, Singh SJ \& Ahlawat YS (1999) Association of a phytoplasma with witches' broom, a new disease of acid lime (Citrus aurantifolia). Current Science 77: 174-177.

Grasso V (1969) Dwarf seedlings from witches' brooms of Pinus halepensis. Italia forestale e montana 24: 241-245.

Johnson AG, Pauley SS \& Cromell WH (1968) Pine dwarf segregates from witches'-brooms. Proceedings of the International Plant Propagators' Society 18: 265-270.

Kraemer MJ \& Nyland RD (2010) Hardwood crown injuries and rebuilding following ice storms: a literature review. General Technical Report NRS-60. Newtown Square, PA: U.S. Department of Agriculture, Forest Service, Northern Research Station. doi:10.2737/NRS-GTR-60.

Liernur AGM (1927) Hexenbesen: ihre morphologie, anatomie und entstehung. Nijgh en Van Ditmar, Rotterdam.

Martínez-Vilalta J, Vanderklein D \& Mencuccini M (2007) Tree height and age-related decline in growth in Scots pine (Pinus sylvestris L.). Oecolo- gia 150: 529-544. doi:10.1007/s00442-006-05527 .

Matsushita M, Takata K, Hitsuma G, Yagihashi T, Noguchi M, Shibata M \& Masaki T (2015) A novel growth model evaluating age-size effect on longterm trends in tree growth. Functional Ecology 29: 1250-1259. doi:10.1111/1365-2435.12416.

Ozturk M, Coskuner K., Usta Y, Serdar B \& Bilgili E (2019) The effect of mistletoe (Viscum album) on branch wood and needle anatomy of Scots pine (Pinus sylvestris). IAWA Journal 40: 352-365. doi:10.1163/22941932-40190219.

Rigling A, Eilmann B, Koechli R \& Dobbertin M (2010) Mistletoe-induced crown degradation in Scots pine in a xeric environment. Tree Physiology 30: 845-852. doi:10.1093/treephys/tpq038.

Savidge RA (2001) Intrinsic regulation of cambial growth. Journal of Plant Growth Regulation 20: 52-77. doi:10.1007/s003440010002.

Schweingruber FH (1988) Tree rings: basics and application of dendrochronology. Kluwer Academic Publishers, Dordrecht, Boston, London.

Schweingruber FH (1996) Tree rings and environment. Dendroecology. Swiss Federal Institute for Forest, Snow and Landscape Research, WSL/ FNP; Paul Haupt, Birmensdorf, Berne.

Waxman S (1975) Witches'-brooms' sources of new and interesting dwarf forms of Picea, Pinus, and Tsuga species. Acta Horticulturae: Symposium on Propagation in Arboriculture 54: 25-32.

Yamburov MS \& Goroshkevich SN (2007) Witches'-brooms in Siberian stone pine as somatic mutations: occurrence, features and possibility of using in breeding programs. Khvoynyye borealnoy zony 24: 317-324.

Yamburov MV, Prokopyev AS, Astafurova TP \& Ponkratyeva SV (2016) The development of mutational witches' brooms in Scotch pine (Pinus sylvestris). Asian Journal of Microbiology, Biotechnology and Environmental Science 18: 911-917.

Yan CF, Gessler A, Rigling A, Dobbertin M, Han XG \& Li MH (2016) Effects of mistletoe removal on growth, $\mathrm{N}$ and $\mathrm{C}$ reserves, and carbon and oxygen isotope composition in Scots pine hosts. Tree Physiology 36: 562-575. doi:10.1093/treephys/ tpw024.

Yun HY, Hong SG, Rossman AY, Lee SK, Lee KJ \& Bae KS (2009) The rust fungus Gymnosporangium in Korea including two new species, G. monticola and G. unicorne. Mycologia 101: 790-809. doi:10.3852/08-221.

Zhuk E, Vasilyeva G \& Goroshkevich S (2015) Witches' broom and normal crown clones from the same trees of Pinus sibirica: a comparative morphological study. Trees 29: 1079-1090. doi:10.1007/s00468015-1187-2. 